\title{
THE EFFICACY OF EXTERNAL ROTATION METHOD FOR THE REDUCTION OF ACUTE ANTERIOR SHOULDER DISLOCATION WITH AND WITHOUT GREATER TUBEROSITY FRACTURE
}

\author{
Gnawali GP'*, Dhakal I, ${ }^{1}$ Khatri $K^{2}{ }^{2}$ Sharma $K^{3}$
}

\begin{abstract}
Affiliation
1. Consultant Orthopedic Surgeon, Department of Orthopedic, Lumbini Zonal Hospital, Butwal Rupandehi, Nepal.

2. Senior Orthopedic Surgeon, Department of Orthopedic, Lumbini Zonal Hospital, Butwal Rupandehi, Nepal

3. Assistant Professor, Department of community medicine, Devdaha Medical College, Rupandehi.
\end{abstract}

\section{ARTICLE INFO \\ Article History \\ Received : 24 January, 2018 \\ Accepted : 15 May, 2018 \\ Published : 31 August, 2018}

(C) Authors retain copyright and grant the journal right of first publication with the work simultaneously licensed under Creative Commons Attribution License CC - BY 4.0 that allows others to share the work with an acknowledgment of the work's authorship and initial publication in this journal.

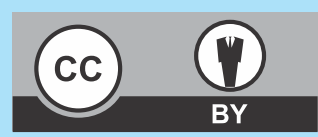

ORA 65

DOI: http://dx.doi.org/10.3126/bjhs.v3i2.20935

\author{
* Corresponding Author \\ Dr Gopal Prasad Gnawali \\ Consultant Orthopedic Surgeon \\ Department of Orthopedic \\ Lumbini Zonal Hospital, Butwal Rupandehi, Nepal \\ Email: gnawaligopal100@yahoo.com \\ ORCID: https://orcid.org/0000-0002-7702-2158
}

\section{Citation}

Gnawali GP, Dhakal I, Khatri K, Sharma K. The Efficacy of External Rotation Method for the Reduction of Acute Anterior Shoulder Dislocation with and without greater tuberosity fracture. BJHS 2018;3(2)6: 408-412.

\section{ABSTRACT}

\section{Introduction}

Several methods of reduction technique have been described for the anterior dislocation of shoulder but none technique is said to be ideal. The aim of this study was to show the efficacy of external rotation method which could be safe and painless method for the reduction of the acute anterior shoulder dislocation with or without fracture of the greater tuberocity and to search the cause of failure of reduction.

\section{Objective}

Objective of this study was to assess the efficacy of the external rotation method for reduction of acute anterior shoulder dislocation and to find the cause of failure of reduction.

\section{Methodology}

All cases of anterior dislocation encountered in emergency department reduced by external rotation method by consultant orthopedic surgeon using basic emergency setting for resuscitation were included in the study. Fifty cases of shoulder dislocation was treated by this method and prospective evaluation done with regard to type of dislocation, the effectiveness of the procedure in achieving reduction, the need for pre-medication, the ease of performing reduction and complication if any.

\section{Results}

Out of 50 cases, successful reduction was achieved in 42 patients. Premedication was not required in 36 successful reduction. Average time of reduction was 2 minutes in 30 patients and 5 minutes in 8 patients. Four Patients complained severe pain during reduction process. This method was not successful in 8 patients 2 of whom had displaced greater tuberocity fracture.

\section{Conclusion}

The external rotation method is reliable and safe method for the reduction of acute anterior shoulder dislocation which can be performed relatively with less pain for both subcoracoid and subglenoid dislocation provided there is no displaced fracture of the greater tuberocity.

\section{KEYWORDS}

Anterior shoulder dislocation; external rotation; greater tuberocity fracture. 


\section{INTRODUCTION}

Almost fifty percents of all joints dislocation presenting in emergency department accounts for shoulder dislocation and most of them are anterior (90 to $98 \%$ ). Some of them are associated with greater tuberocity fracture and Hill Sacs compression defect. ${ }^{1}$

There are several techniques which are being practiced traditionally for the reduction of dislocated shoulder joint. Most of them are painful and some are complicated with further trauma. ${ }^{2-4}$ The ideal choice of reduction should be simple, painless and safe. External rotation method is considered as a new technique which has been claimed to be safe, comfortable and reliable ${ }^{5}$.

The effectiveness of external rotation method in achieving reduction of different type of anterior dislocation of shoulder has not been tested in this part of population. So the aim of this study was to assess the efficacy of external rotation method for successful reduction of anterior shoulder dislocation.

\section{METHODOLOGY}

This was an prospective and cross-sectional study conducted in Department of Emergency and Department of Orthopedic, Lumbini Zonal Hospital and Meditech International Hospital, Butwal. The duration of study was June 2016 to Nov 2017. Ethical approval was obtained from the institution before beginning of the study. Inform consent was taken from every patient included in the study. We treated total 50 cases of anterior shoulder dislocation by this method. All patients were treated by consultant orthopedic surgeon only and they were requested to use this method initially. The diagnosis was confirmed by clinical examination and radiography in AP and axillary view.

All patients with acute anterior dislocation of the shoulder with or without greater tuberociy fracture were included in the study. Exclusion criteria were, patients with polytrauma, hemodynamic instability, dislocation associated with Neer three-part, four-part or head splitting proximal humerus fracture, dislocation with severe glenoid fracture, patients with open growth plate and patients presenting more than twenty four hour after injury.
A proforma containing demographic, radiological, clinical, past history and therapeutic details were filled which contained name, age/sex, address, mechanism of injury, duration of injury, side of dislocation, dominant side, type of dislocation+/-fracture, previous history of dislocation, any previous attempts for reduction, need of premedication before the procedure, time taken for reduction, number of attempts, any alternate procedure used when this method was failed, Pain during reduction was noted. The patient was asked to rate the amount of pain during the process of reduction as none, mild, moderate, or severe, and these ratings were given a score on a 4-point scale with 1 indicating no pain and 4 , severe pain ${ }^{6}$ and finally complications, such as axillary nerve injury, vascular injury and iatrogenic fracture were clearly documented.

Shoulder reduction was attempted by external rotation method using standard technique. ${ }^{6}$ Premedication was given to patients who felt unbearable pain during reduction maneuver for which $5 \mathrm{ml}$ of $2 \%$ lignocaine injection given intra-articular and waited for 5 minutes for its effect. Traction was avoided. The reduction was confirmed by clinical examination, and neurovascular status of the limb was re assessed. The shoulder was immobilized by immobilizer in adduction and internal rotation and sent for radiographs to confirm the reduction.

Patients with successful reduction were sent home with medication and advised to follow up after two weeks and those with unsuccessful reduction were planned for reduction under $\mathrm{GA}$.

\section{RESULTS}

There were 54 patients who were treated for anterior dislocation during study period, 33 patients were from Lumbini Zonal Hospital and twenty one were from Meditech Hospital. Out of them only 50 patients were included in the study and 4 cases were excluded. In the exclusion group, first patient had open physis, second patient had associated poly trauma, third patient had anterior dislocation with proximal humerus fracture and fourth patient had associated lacerated arm which required debridement under GA. Commonest mechanism of injury was fall on an outstretched hand (74\%).

Table 1: Important observatory findings

Male/ female ratio

Mean age of presentation

Right shoulder/ Left shoulder ratio

Dominant side/ Non dominant side ratio

First time dislocation/Recurrent dislocation ratio

Sub coracoid dislocation/Sub glenoid dislocation

Dislocation only/ Dislocation with GT fracture

Mean time of arrival

Reduction achieved within two minutes

Mean duration of hospital stay
33 (66\%): 17(34\%)
42 yrs (19 to 80 yrs)
41(82\%): 9(18\%)
30(60\%): 18(36\%)
44(88\%):6(12\%)
38(76\%):12(24\%)
36(72\%): 14(28\%)
6 hour(1-24hrs)
$30(71 \%)$
1.6 hour ( 30 minutes to 3 hour) 
Table 2: Reduction achieved by using External Rotation method

\begin{tabular}{|c|c|c|}
\hline Closed reduction & Successful & Unsuccessful \\
\hline Sub coracoids (38) & $32(84 \%)$ & $5(16 \%)$ \\
\hline Sub glenoid (12) & $10(83 \%)$ & $3(17 \%)$ \\
\hline Total (50) & $42(84 \%)$ & $8(16 \%)$ \\
\hline
\end{tabular}

Table 4: Need of premedication

\begin{tabular}{|l|c|c|}
\hline Premedication & Successful reduction & $\begin{array}{c}\text { Un Successful } \\
\text { Reduction }\end{array}$ \\
\hline Used & $6(14 \%)$ & $8(100 \%)$ \\
\hline Not used & $36(86 \%)$ & 0 \\
\hline
\end{tabular}
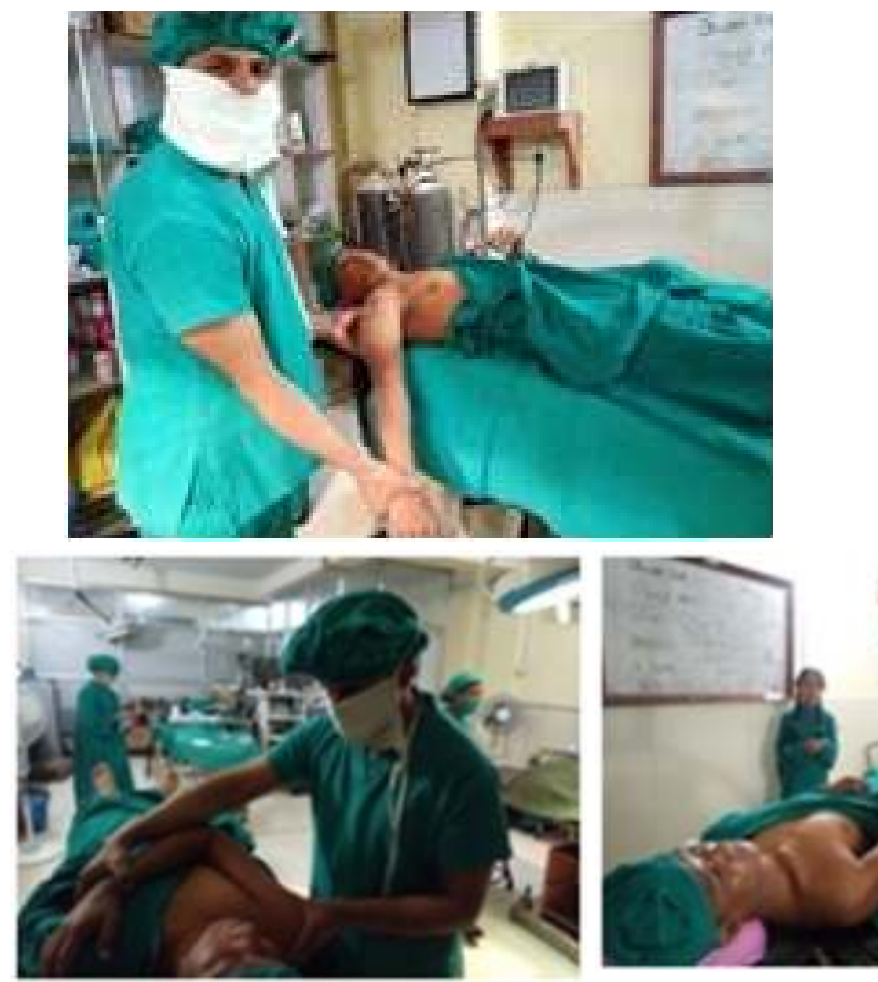

Figure 2: Reduction maneuver.
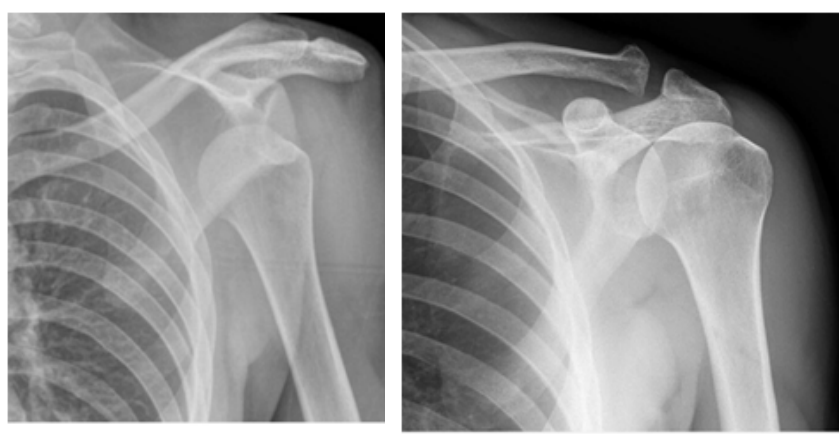

Figure 3: Pre and post reduction X-Rays

Reduction was achieved with this method in 30 dislocations within two minutes and in 12 dislocations within five minutes. Premedication was not used in 36 reductions and this was used only when any attempt (procedure) without premedication failed. We used $5 \mathrm{ml}$ of $2 \%$ plain lignocaine intraarticularly and waited for 5 minutes. Premedication was used in 14 cases out of them 6 patients had successful reduction. Out of 36 successful reductions achieved
Table 3: Relation of successful reduction and greater tuberocity fracture

\begin{tabular}{|c|c|c|c|c|c|c|}
\hline $\begin{array}{c}\text { Type of } \\
\text { Dislocation }\end{array}$ & Sub corc & oids (38) & Subgle & oid (12) & Tot & (50) \\
\hline GT fracture & Absent & Present & Absent & present & Absent & Present \\
\hline Total & 28 & 10 & 8 & 4 & 36 & 14 \\
\hline $\begin{array}{l}\text { Successful } \\
\text { reduction }\end{array}$ & $25(89 \%)$ & $8(80 \%)$ & $8(100 \%)$ & $1(25 \%)$ & 33(91\%) & $9(64 \%)$ \\
\hline $\begin{array}{l}\text { Unsucessful } \\
\text { reduction }\end{array}$ & $3(11 \%)$ & $2(20 \%)$ & $0(0 \%)$ & $3(75 \%)$ & $3(9 \%)$ & $5(36 \%)$ \\
\hline
\end{tabular}

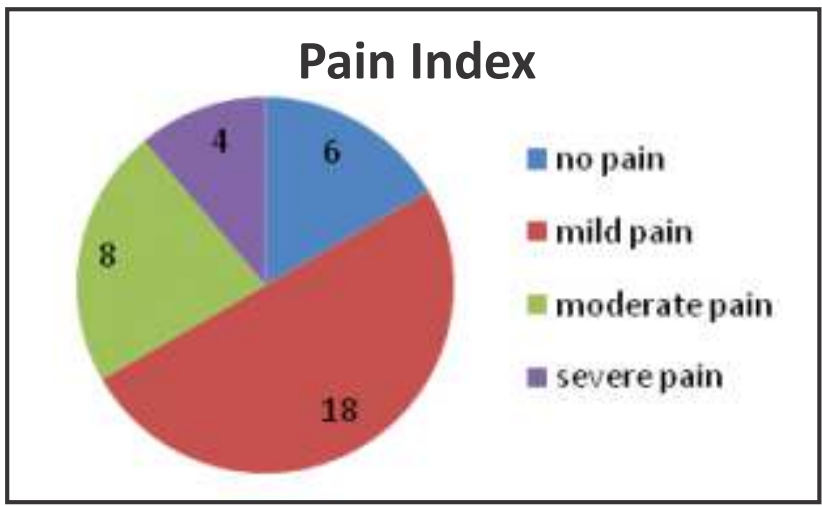

Figure 1: Pain felt by the patients when premedication was not used.

without premedication, 6 patients had no pain, 18 patients had mild pain, 8 patients had moderate pain and 4 patients had severe pain. Out of these four patients, who experienced severe pain during reduction process, three patients had associated greater tuberocity fracture. Complication was not noted in any cases in this study.

\section{DISCUSSION}

Acute anterior shoulder dislocation is a very common disorder for orthopedic surgeon and emergency doctor. Older methods of reduction used traditionally are often technically difficult, painful and time consuming. Additionally, these methods frequently require two persons and sometimes the injury can be exacerbated by these methods. Conversely, the described method of reduction by external rotation is safe, reliable, can be performed rapidly by a single physician and patient can tolerate it well. ${ }^{6}$

This study showed that external rotation method is effective and reliable method for the closed reduction of acute anterior dislocation of shoulder. This procedure was 
reproducible and easily acceptable by both patients and surgeons. We were able to achieve the closed reduction in $84 \%$ of the patients which is almost similar to the rate reported by Mirick et al. ${ }^{7}$, who also used the same technique.

The beauty of this method is effective, reliable, safe, causing minimal discomfort to the patient and requiring only a single physician to perform it. ${ }^{5}$ External rotation method is more or less similar method described by the Kocher ${ }^{8}$. In our study we kept the patient in supine position and arm was adducted, by keeping the elbow in right angle, forward flexion of the shoulder done by 20 degree. The difference in our technique is that we kept the shoulder in forward flexion in compared with the original technique of external rotation described by the Leidelmeyer ${ }^{9}$ The forward flexion of the shoulder was done to facilitate relaxation of the anterior capsule and to prevent any bowstring action of the long head of biceps and the conjoint tendons. As described by the Jahir et al., "Gentle but sustained external rotation was used to neutralize the medially directed contraction force of the subcapsularis and the pectoralis major muscle, which are the main obstacles to the lateral displacement of humeral head." ${ }^{10}$

Traction is commonly used in other reduction method which is not used in this method. The disadvantage of traction is that it increases the muscular spasm which could make the reduction more difficult the procedure would be painful and the reduction couldn't be achieved. ${ }^{11}$ Medirik et al. ${ }^{7}$ and Leidelmeyer ${ }^{9}$ advised the use of intravenous sedation in patients with first episode of dislocation; however in our series, 36 out of 42 reduction was achieved without premedication. Using other method, authors have reported greater failure rate with subcoracoid dislocation ${ }^{12,13}$ and sub glenoid dislocation ${ }^{14}$ unlike in our series where the rate of reduction of subcoracoid and sub glenoid dislocation was similar.

We could not reduced eight dislocations by this method. Out of 8 unreduced dislocations, 5 were associated with displaced greater tuberocity fracture which signifies the initial greater trauma of bone and soft tissue. Hemarthrosis and marked muscle spasm may have contributed for the unsuccessful reduction. A study by Ceroni D et al. ${ }^{14}$ also recommended that, in sub glenoid dislocation associated with a fracture of greater tuberocity, the initial reduction should be under the general anesthesia to avoid the complications like iatrogenic fracture of anatomical neck of the of the humerus. We do agree with this recommendation and our data also shows the same scenario.

\section{REFERENCES}

1. Blake R, Hoffman J. Emergency department evaluation and treatment of shoulder and humerus. Emerg Med Clin North Am 1999;17:859-76. PMID:10584106

2. Beattle TF,Steedman DJ, Mc Gowen A,Robertson CE. A comparision of the Milch and kocher technique for acute anterior dislocation of shoulder. Injury.1986;17:349-52. PMID:3533776

3. Janecki CJ, Shahcheragh GH. The forward elevation maneuver for reduction of anterior dislocation of the shoulder. ClinOrthop. 1982;164:177-80. PMID:7067281
We did not compare the external rotation method with any other method for efficacy, safety and patients comfort. In our study, all patients underwent external rotation method without any choice. There is possibility of selection bias in this study because the physician preselected patients in whom they thought this method would be successful. The number of patient included in this study was very few and the duration of study was for a short period. We did not encounter any short term complication in our series which confirm the safety of this method.

\section{CONCLUSION}

The external rotation method is rational, simple, and relatively pain free method to reduce an acute anterior dislocation of shoulder. It can be used successfully to reduce both subcoracoids and subglenoid dislocation without displaced greater tuberocity fracture.

\section{RECOMMENDATION}

The author suggests applying this method to treat every cases of acute anterior dislocation of shoulder. This method has been tested in many population in different area of the globe. This is effective, easy and reliable.

\section{LIMITATION OF THE STUDY}

We did not compare the external rotation method with any other method for efficacy, safety and patients comfort. In our study, all patients underwent external rotation method without any choice. There is possibility of selection bias in this study because the physician preselected patients in whom they thought this method would be successful. We studied the limited number of patient for limited time.

\section{ACKNOWLEDGEMENT}

The authors would like to thank Mr Bhagirath Rana, Mrs Sarita Sharma for the collection and arrangement of cases. The authors would also like to acknowledge the participants without whom the study would not have been possible.

\section{CONFLICT OF INTEREST}

There was not any conflict of interest from the authors and participants.

\section{FINANCIAL DISCLOSURE}

None
4. Manes HR. A new method of shoulder reduction in the elderly. Clin Orthop 1980;(147):200-2. PMID:7371296

5. Plummer D,Clinton J. The external rotation method for reduction of acute anterior shoulder dislocation. Emerg Med Clin North Am. 1989; 7:165-75. PMID:2917505

6. W W Downie, P A Leatham, V M Rhind, V Wright, J A Branco and J A Anderson. Studies with pain rating scales. Ann Rheum Dis. 1978 Aug;37(4):378-81. PMID: 686873. 
7. Mirick MJ, Clinton JE. Ruiz E. External rotation method of shoulder dislocation.JACEP.1989; 8: 528-31. DOI:10.1016/S0361-1124(79) 80302-0

8. Uglow M G, Kocher's painless reduction of anterior dislocation of the shoulder: a prospective randomized trial. Injury 1998;29(2): 135-37. PMID: 10721408

9. Leidelmeyer R. Reduced! A shoulder, subtly and painlessly. Emerg Med.1977;9:233-4.

10. Zahiri C A,Zahiri H,Tehrany F. Anterior shoulder reduction technique-revisited.Orthopedcs.1997;2:515-21.PMID 9195634

11. Ghane Mohammad et al,Comparision between traction-countert raction and modified scapular manipulation for reduction of shoulder dislocation, Chinese Journal of traumatology 2014;17(2):93-98. DOI: 10.3760/cma.j.issn.1008-1275.2014.02.
12. Canales Cortes V, Garcia-Dihinix Checa L, Rodriguez Vela J. Reduction of acute anterior dislocation without anaesthesia in a position of maximum muscular relaxation. Int Orthop. 1989;13: 259-62. DOI: 10.1007/BF00268508

13. Garnavos C. Technical note: Modification and improvements of Milch technique for the reduction of anterior dislocation of shoulder without premedication. J Trauma.1992;32:81-3. PMID:1613841

14. Ceroni D, Sadri H, Leueberger A. Radiographic evaluation of anterior dislocation of shoulder. Acta Radiol.2000:41:685-61. PMID:11092493 Leidelmeyer R. Reduced! A shoulder, subtly and painlessly. Emerg Med.1977;9:233-4. 